
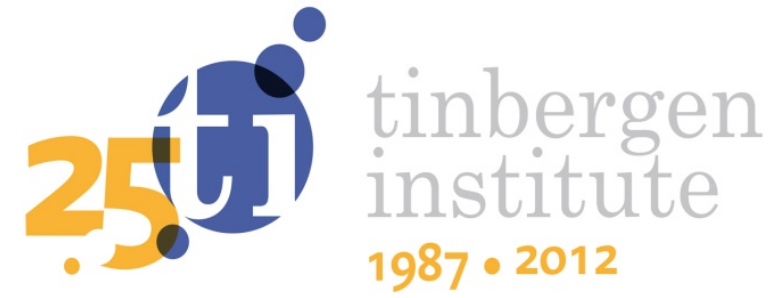

\title{
The Influence of Wages on Public Officials' Corruptibility: A Laboratory Investigation
}

\author{
R. van Veldhuizen
}


Tinbergen Institute is the graduate school and research institute in economics of Erasmus University Rotterdam, the University of Amsterdam and VU University Amsterdam.

More TI discussion papers can be downloaded at http://www.tinbergen.nl

Tinbergen Institute has two locations:

Tinbergen Institute Amsterdam

Gustav Mahlerplein 117

1082 MS Amsterdam

The Netherlands

Tel.: +31(0)205251600

Tinbergen Institute Rotterdam

Burg. Oudlaan 50

3062 PA Rotterdam

The Netherlands

Tel.: +31(0)10 4088900

Fax: $+31(0) 104089031$

Duisenberg school of finance is a collaboration of the Dutch financial sector and universities, with the ambition to support innovative research and offer top quality academic education in core areas of finance.

DSF research papers can be downloaded at: http://www.dsf.nl/

Duisenberg school of finance

Gustav Mahlerplein 117

1082 MS Amsterdam

The Netherlands

Tel.: +31(0)20 5258579 


\title{
The influence of wages on public officials' corruptibility: a laboratory investigation
}

\author{
R. van Veldhuizen ${ }^{\mathrm{a}, 1, *}$ \\ ${ }^{a}$ Roetersstraat 11, $1018 \mathrm{WB}$ \\ Amsterdam, Netherlands
}

\begin{abstract}
Previous studies have proposed a link between corruption and wages in the public sector. This paper investigates this link using a laboratory experiment. In the experiment, public officials have the opportunity to accept a bribe and can then decide between a neutral and a corrupt action. The corrupt action benefits the briber but poses a large negative externality on a charity. The results show that increasing public officials' wages greatly reduces their corruptibility. In particular, experienced low wage public officials accept $91 \%$ of bribes on average, whereas high wage public officials accept 38\%. Moreover, high wage public officials are less likely to choose the corrupt option.
\end{abstract}

Keywords: Bribery, Corruption, Experimental Economics, Laboratory Experiment

JEL Classification: D73, C91, K42

\section{Introduction}

Corruption is a significant problem in large parts of the world. ${ }^{2}$ As a consequence, fighting corruption has at least ostensibly become a primary goal for many of the world's governments. ${ }^{3}$ One possible policy instrument that has prompted considerable debate is the level of public official compensation. Theory (starting with Becker and Stigler, 1974) suggests that increasing the wages of public officials should reduce their corruptibility. If this relationship holds, it provides governments with a policy instrument that falls directly under its control and would therefore be relatively easy to implement.

*Tel: +31205254383 / Fax: +31 20525 5283. An earlier version of this paper was circulated under the title "Bribery and the Fair Salary Hypothesis in the Lab".

${ }^{1}$ University of Amsterdam and the Tinbergen Institute.

${ }^{2}$ See Svensson (2005) for an overview of several studies that find a detrimental effect of corruption on economic performance.

${ }^{3}$ As just one example, over the past year the Indian government has repeatedly emphasized the importance of fighting corruption, see for example http://www.nytimes.com/2011/02/17/world/asia/17india.html. 
However, empirical evidence for this relationship has been hard to come by. Since corrupt activities are usually not incorporated into official accounts, direct measures of corruption are only rarely available. As a consequence, empirical studies on corruption have often been forced to rely on indirect measures of corruption. Additionally, even if more direct measures of corruption are available, establishing causality may still be problematic. Laboratory experiments allow us to obtain a more direct measure of corruption as well as establish causality. This paper presents the results of a laboratory experiment in which participants in the role of public officials either accept or reject a bribe and then decide between a neutral and a corrupt action. The corrupt action benefits the briber but poses a large negative externality on a charity. In the experiment, I exogenously vary public officials' wages and find that increasing public officials' wages reduces their corruptibility. In particular, it makes experienced public officials 53 percentage points less likely to accept a bribe on average and reduces the number of corrupt choices by 27 percentage points.

The remainder of the paper is organized as follows. The next section provides a discussion of related studies as well as possible mechanisms that can explain the link between wages and corruption. Section three then provides an overview of the bribery model that forms the basis of the experiment. Section four covers the design of the experiment and section five explains the experimental hypotheses. Section six presents the results of the experiment and in section seven I provide the results of a robustness check that shows that a nonzero level of monitoring may be necessary for the link between wages and corruptibility to appear. Section eight provides a short discussion of the results.

\section{Background}

Previous studies have suggested at least two reasons why increasing public officials' wages could reduce the level of corruption. Firstly, increasing public official salaries may increase the expected monetary costs of corruption. A wage increase will reduce the relative value of the wage a public official could expect to earn in the private sector. Under the right combination of monitoring and punishment, the expected loss from corruption for public officials will increase, inducing them to behave less corruptly (This is the mechanism suggested by Becker and Stigler, 1974; see also Olken, 2007).

\footnotetext{
${ }^{4}$ An additional mechanism applies if public officials' utilities are a concave function of money. Having a large salary will then decrease their marginal utility of money, decreasing the attractiveness of accepting bribes.
} 
Increasing public officials' wages may also increase the nonmonetary or 'moral' costs of corruption. There are at least three reasons why nonmonetary costs of corruption could be increasing in the wage of public officials. Firstly, public officials may perceive a high wage as more fair, making it more costly for them to go against the government's wishes by behaving corruptly; this idea is similar to the fair wage-effort hypothesis (Akerlof and Yellen, 1990; see also Van Rijckeghem and Weder, 2001). Secondly, there may be a social norm condoning side payments for low wage public officials but not for high wage public officials (Fisman and Miguel, 2007). Thirdly, inequality averse public officials may be more willing to increase their income through corruption if their wage is lower than the comparison wage (Fehr and Schmidt, 1999; Abbink, 2002).

However, field studies have produced little evidence in favor of the link between corruption and public sector salaries. I found four directly relevant empirical studies, which are also discussed in Svensson (2005). These studies are Rauch and Evans (2000), Treisman (2000), Van Rijckeghem and Weder (2001) and Di Tella and Shargrodsky (2003). Of these four, the first two find no robust evidence; the latter two find a small negative association. However, as Svensson argues, the the first three studies are based on cross-country data that make it hard to establish causality; moreover they use ranked data rather than absolute levels to measure corruption. Di Tella and Schargrodsky (2003) make use of exogenous variation in the audit probability in the city of Buenos Aires, which increases the risks involved in corruption and does directly not affect the relative wage of public officials.

In response to this apparent difficulty in acquiring high quality data, the last decade has seen a large increase in the number of laboratory experiments in the area of corruption. Lab experiments can be used as a substitute for field data when field data are not available or of low quality -as is often the case in the area of corruption. Even if good field data are available, lab experiments can serve a complementary role by presenting an environment with a level of control and noiselessness that cannot be achieved in the field. Starting with Frank and Schulze (2000) and Abbink et al. (2002), corruption experiments have investigated issues ranging from the effect of staff rotation (Abbink, 2004), culture (Barr and Serra, 2010; Cameron et al., 2009) and intermediaries (Drugov et al., 2011) to the effect of different voting systems (Azfar and Nelson, 2007); see Abbink (2006) for an overview.

Laboratory experiments have also previously been used to investigate the influence of public officials' wages on their corruptibility. Abbink (2002) investigated the link between wages and corruption by varying the wage of pub- 
lic officials with respect to the wage of a third party and found no effect. Armantier and Boly (2008) compare the results of a framed lab and field experiment in which participants have to grade homeworks. In one of the homework sets, graders receive a bribe accompanied by a request to be lenient in grading. They find that increasing graders' wages decreases their corruptibility, although this effect is significant only in the lab with a large set of controls. Azfar and Nelson (2007) find that higher wages decrease the corruption of an executive party in a public choice experiment but have no effect on the corruptibility of an attorney general. Finally, Jacquemet (2005) studies a three player corruption game with delegation and finds that corruption actually increases in the wage of the public officials. ${ }^{5}$ Overall, the laboratory evidence on the link between wages and corruption thus appears to be rather mixed as well.

One possible reason why previous studies examining the link between wages and corruption have yielded mixed findings is that they have paid only limited attention to the question of what constitutes an appropriate reference wage. Indeed, both monetary and nonmonetary considerations require a reference wage to determine what wage should be regarded as a 'high' wage and what wage constitutes a 'low' wage. Previous field studies have tended to take aggregate level variables as reference wages, such as for example the average wage in the manufacturing sector (e.g. Van Rijckeghem and Weder, 2001). However, previous work in both psychology and economics suggests that people compare themselves to individuals who are similar to them, whom they often interact with and who are salient at the moment a comparison is made (see e.g. Festinger, 1954; Buunk and Mussweiler, 2001; Suls et al., 2002; Sweeney and McFarlin, 2004; or see Linde and Sonnemans, 2012 for a recent application in economics).

For income comparisons colleagues or other people encountered in work environments are the most likely reference points. A typical economist for example may compare her wage to economists of a similar age, working in the same field and possibly at the same or similar level universities. For public officials on the verge of deciding whether or not to take a corrupt action, people in the work environment are either colleagues or people that require their service (i.e. potential bribers). At the time of a bribe, the focus on the potential briber is likely to be particularly strong since public officials in direct personal contact

\footnotetext{
${ }^{5}$ Jacquemet conjectures that this is caused by the fact that being corrupt is costly in the experiment, so that high wage public officials can more easily afford to be corrupt. Barr et al. (2009) also document a link between public officials' wages and corruption in a laboratory experiment. However, in this study the monitoring rate is endogenously determined and increasing in the public official's wage; hence it becomes impossible to separate the effect of wages on corruptibility from the effect of monitoring.
} 
with bribers at the time a bribe takes place. Moreover, through bribing public officials and bribers can influence each others' incomes, making the income comparison between bribers and public officials especially salient. By contrast, aggregate variables such as the average wage in the private sector are abstract (and possibly unknown) and therefore not likely to be salient and the object of an income comparison.

This suggests that the salience of the reference wage should be regarded as an important matter also in experimental studies. In particular, the use of different reference wages may explain the mixed results reported in previous studies. Of the aforementioned experimental studies, only Abbink (2002) explicitly introduces a reference wage in the experiment. He varies the reference wage by varying public officials' wages with respect to the wages of a third party and finds no effect. However, the third party in this study had no role in the experiment other than to absorb negative externalities. ${ }^{6}$ Hence, the third party may not have been very salient to the public official at the time of the bribery decision and may thus not have served as a reference point. ${ }^{7}$ Armantier and Boly (2008), citetAzfar2007 and Jacquemet (2005) do not explicitly address what constitutes the appropriate reference wage in their experiments, which may explain the mixed findings between these studies.

Thus, this paper contributes to the experimental literature in at least two ways by studying the relationship between the relative wage of public officials and their corruptibility by using a salient (and perhaps more natural) reference wage in the experiment. Additionally, it introduces a new way of implementing corruption in the lab by deducting money from a charity fund every time public officials make a corrupt decision; the latter point will be discussed in greater detail in the next section.

\section{The Bribery Model}

To study bribery in an experimental context, I use an adapted version of the experimental bribery game (Abbink et al., 2002). The experimental bribery game describes a situation in which a citizen (or firm) can use a bribe to attempt to convince a public official to select a favorable action (or policy) to implement. This reflects for example situations where a citizen needs to acquire a driver's

\footnotetext{
${ }^{6}$ The third party was performing a useful task, but not one that was related to the experimental situation the public official and the potential briber were partaking in.

${ }^{7}$ Additionally, since the third party consisted of laboratory subjects not contributing to the group income, some public officials may have felt that the third party deserved a punishment for not being productive.
} 
license or needs a construction permit to build a new home. Importantly, the action that is favorable to citizens imposes a negative externality on society, as is the case for instance if the citizen is an incapable driver or wants to build a new house in a protected forest area.

The experiment is a repeated game of 25 periods. In the stage game (displayed in figure 1), the citizen (C) decides whether to offer a transfer (or bribe) of a nonnegative integer amount $t$ to the public official $(\mathrm{P})$. If a positive transfer has been offered (i.e. if $t>0$ ), the public official decides whether to accept or reject the transfer. If the public official has decided to accept the offer, there is a small probability (.003) that both players are caught and receive a punishment. To mimic the possibly large fines and job loss associated with getting caught in the corrupt act in practice, the punishment in the experiment is set to the largest feasible level. This means that players who are caught are disqualified from the experiment, which means that they lose all their earnings in the current and preceding periods and are not allowed to participate in subsequent periods. $^{8}$

Provided that players have not been disqualified, the public official can then choose between two alternatives $\mathrm{G}$ and $\mathrm{B}$. Here $\mathrm{G}$ is a status quo action and B is a corrupt alternative. Option $\mathrm{B}$ is a genuinely corrupt option, since choosing it will take money away from a good cause (a charity). However, a selfish citizen strongly prefers option B to option G to represent the gains to corruption. Option B is also slightly less favorable to the public official to represent the idea that she will need to exert some effort to justify a 'corrupt' choice to her superiors.

Allowing the cost of corruption to be imposed on a charity represents a new approach in the literature. Using a charity as the victim of corrupt behavior reflects the way corruption imposes negative externalities on society in the field. In particular, the same way that corruption is almost universally regarded as a bad thing, not many people would condone taking money away from a charity. By contrast, previous experimental studies have largely imposed negative externalities on other laboratory subjects, which may not have such clear negative moral connotations. For example, if a participant in an experiment expects other participant to be corrupt, he may actually feel that they deserve to have money taken away from them.

Returning to the game tree in figure 1, note that the subgame perfect Nash

\footnotetext{
${ }^{8}$ In the experiment, disqualified participants still received a show-up fee of 7 euros. With the probability of punishment set to .003 , pairs with positive transfers in all 25 periods had a probability of of $1-.997^{25}=.072$ of being disqualified.
} 


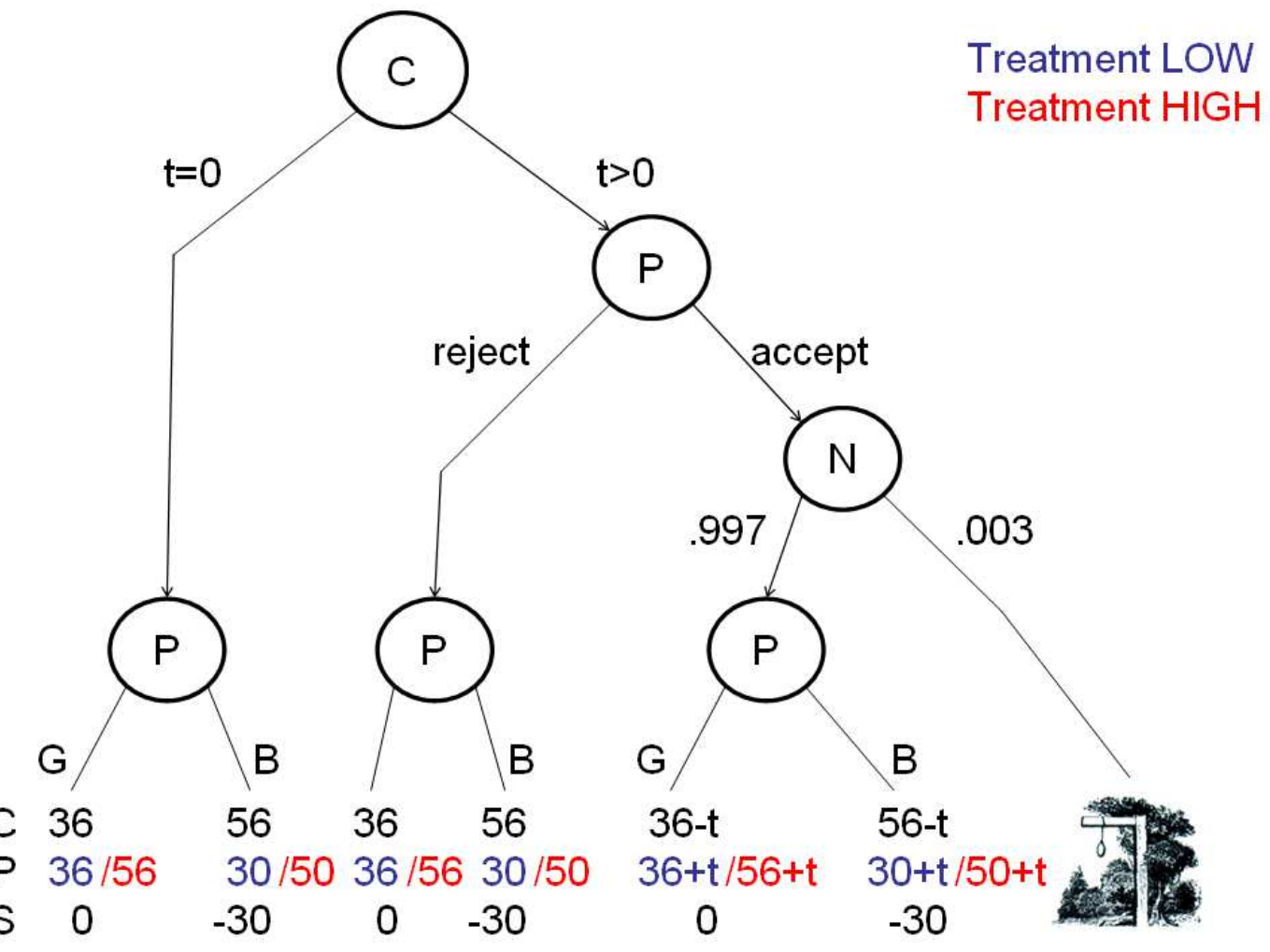

Figure 1: the experimental game tree

equilibrium (for selfish preferences) of the stage game is for the public official to always choose option $\mathrm{G}$ and for no transfers to take place. As the last mover the selfish public official will always choose option $\mathrm{G}$-the option that gives her the highest payoff. As a consequence, the citizen knows that he should not offer a transfer, since offering a transfer can only lower his payoff. ${ }^{9}$ Moreover, Abbink et al. (2002) use a mathematical induction argument to show that the stage game result holds for all periods in a repeated game as well.

The experiment uses two treatments varying with respect to the wage of the public official. Figure 1 gives the pay-offs associated with both treatments. The public official's wage is either equal to the income of the briber in the status quo option G (treatment LOW) or higher (treatment HIGH).

\footnotetext{
${ }^{9}$ Technically this holds only if the citizen expects the public official to accept the transfer with positive probability, otherwise the citizen will be indifferent between proposing and not proposing a transfer.
} 


\section{Experimental Design}

The experiment was conducted with 76 participants over four sessions in June 2010 and June 2011 at the CREED laboratory of the University of Amsterdam. Participants were recruited using an online recruitment procedure. The vast majority were students, with the largest fraction $(52 \%)$ from the economics department.

The experiment itself was computerized using PHP/MySQL. Upon entering the laboratory, subjects were randomly assigned to a computer terminal and received a set of instructions. As part of the instructions, participants went through a set of questions to make sure they fully understood the instructions. The instructions and questions are reproduced in appendix A.

At this point, it is worthwhile to emphasize that the experiment avoided corruption-related words like bribe, citizen or public official. Instead, the experiment refers to the citizen, the public official and a bribe as player 1, player 2 and a transfer respectively. Note, however, that Abbink and Hennig-Schmidt (2006) found no evidence of a framing effect on the results in a bribery experiment that also builds on Abbink et al. (2002).

After finishing the check-up questions participants were asked to choose a charity for the current session. At the beginning of every session, a substantial sum of money (5000 experimental points or 50 Euros) was reserved for a single charity. As part of the instructions, participants were told that every time any public official in the current session chose option B (the corrupt option), this would lower the charity fund by 30 points. At the end of the instructions, participants were asked to pick one charity from a list of five charities that are well-known in the Netherlands. ${ }^{10}$ These were UNICEF, the Dutch Red Cross, the World Wildlife Foundation, Cliniclowns and the Prins Bernhard Cultuurfonds. ${ }^{11}$ They could also specify another charity of their choosing, although they were told that including a controversial charity could lead to the payment being awarded to another charity instead. At the end of the session, the charity

\footnotetext{
${ }^{10}$ Relative to a fixed charity, allowing participants to select from multiple charities made it possible for them to select a charity that fit better with their personal taste. For a fixed charity, it is possible that at least some participants do not care about the chosen charity. Allowing participants to pick their own charity decreases this chance. Since choosing a certain charity increased the chance that this charity would be picked, each participant had the incentive to pick his or her preferred charity.

${ }^{11}$ Of these five charities, the first three are well-known internationally as well. The Cliniclowns are an organization of Dutch clown doctors, who seek to help alleviate some of the stress in seriously ill, hospitalized young children. The Prins Bernhard Cultuurfonds sponsors a wide range of cultural activities in the Netherlands, such as theater, art and the conservation of architectural monuments.
} 
choice of one randomly determined participant was implemented. ${ }^{12}$

After every participant had finished the instructions and check-up questions and chosen a charity, the experiment started. Every session consisted of 25 periods. Before the first period, every participant was told their role (citizen or public official). Their role remained fixed over the whole experiment and public officials were matched to the same citizen for all 25 periods. ${ }^{13}$

Every period in the experiment consisted of five stages (see figure 1). In the first stage, citizens decided whether or not to offer a bribe. Conditional on offering a bribe, they could specify the size of the bribe in stage 2 . In stage 3, public officials decided whether or not to accept the proposed bribe. Conditional on accepting the bribe, stage 4 consisted of a random draw that determined disqualification; disqualified subjects were immediately notified and asked to fill out an unrelated questionnaire for the remainder of the experiment. Finally, in stage 5 public officials had to choose between options G and B. Note that many pairs skipped stages 2, 3 and/or 4 in several periods. For example, citizens who did not offer a bribe would skip stages 2,3 and 4 . The decision screen displayed all possible moves by both players and indicated at what stage the players had currently arrived. The decision screen is reproduced in appendix B.

Every period ended after all pairs had finished the period; for all pairs the waiting screen between periods displayed the results of all preceding periods for the given pair. After 25 periods, one subject was randomly picked to roll a die to determine the winning charity. Participants then received an overview of their earnings and were asked to fill out a questionnaire. The questionnaire contained background questions, motivational questions, a questionnaire related to corruption taken from Rabl and Kühlmann (2008) and a psychological questionnaire relating to aggression (Buss and Perry, 1992). Upon finishing the questionnaire, participants were paid their earnings (including a show-up fee of 7 euros) and were kindly requested to leave the laboratory.

Participants earnings ranged from 14.14 to 23.70 euros with an average of 17.63 euros. Charities earned between 20.60 and 41.90 euros, with an average of 31.40 euros. In total every session lasted approximately 75 minutes (15 minutes for the instructions, 30 minutes for the decision problem and 30 minutes for the

\footnotetext{
${ }^{12}$ The number of participants that chose UNICEF, the Red Cross, the WWF, the Cliniclowns, the Prins Bernhard Cultuurfonds and another charity was equal to $34,15,14,6,1$ and 6 respectively. None of the 6 alternative charities were too controversial to exclude. The winning charities were the Red Cross (once) and the WWF (three times).

${ }^{13}$ In other words the experiment used a partners design. See Abbink (2004) for an experimental analysis of the effect of using partners or strangers design in a bribery experiment.
} 
questionnaire plus payment). Since no feedback from other pairs was given to participants, the number of independent observations is equal to 38 .

\section{Hypotheses}

This study examines the relationship between an increase in the relative wage of public officials and their corruptibility. ${ }^{14}$ There are at least two reasons for high wage public officials to be more reluctant to accept a bribe. Firstly, they may face higher non-monetary costs of corruption. Inequality averse (Fehr and Schmidt, 1999) public officials will for example note that accepting a bribe in treatment LOW may decrease disadvantageous inequality (a good thing), whereas accepting a bribe in treatment HIGH will increase advantageous inequality (a bad thing). Public officials who care about status can guarantee themselves a higher income level than the briber without accepting a bribe in treatment HIGH, in treatment LOW a large bribe is necessary to guarantee a higher income level than the briber. Secondly, public officials in treatment HIGH have more to lose from accepting a bribe if caught (i.e. a higher monetary cost). Both monetary and non-monetary mechanisms lead to the following hypothesis. ${ }^{15}$

Hypothesis 1: Public officials are less likely to accept a bribe in treatment HIGH than in treatment LOW.

If the monetary and nonmonetary costs of corruption are increasing in the public official's relative wage, then the frequency of corrupt (B) choices should decrease as well. The bribery relationship is a reciprocal relationship between a briber and a public official. Public officials who want to continue a bribery relationship should pick option $\mathrm{B}$ after accepting a bribe to reciprocate the briber. If hypothesis 1 holds, public officials in treatment HIGH are less likely to accept bribes. Thus, there will be less reason for them to maintain the bribery relationship, which means they should be less likely to pick option B. This leads us to the next hypothesis.

\footnotetext{
${ }^{14}$ In the remainder of the paper I will focus mostly on the behavior of public officials. The reasons for deemphasizing citizens are that citizen behavior (a) is not directly relevant to the link between the wages and corruptibility of public officials, (b) is less interesting in scope (only a transfer offer) and (c) crucially depends on how citizens expect public officials to behave (in contrast to public officials, who already know the behavior of the citizen by the time they have to make their decisions).

${ }^{15} \mathrm{~A}$ possible third mechanism could be that public officials' utility functions are concave in money. However, this mechanism is unlikely to have a large bite in the experiment since for small amounts it is reasonable to assume that utility functions are approximately linear.
} 


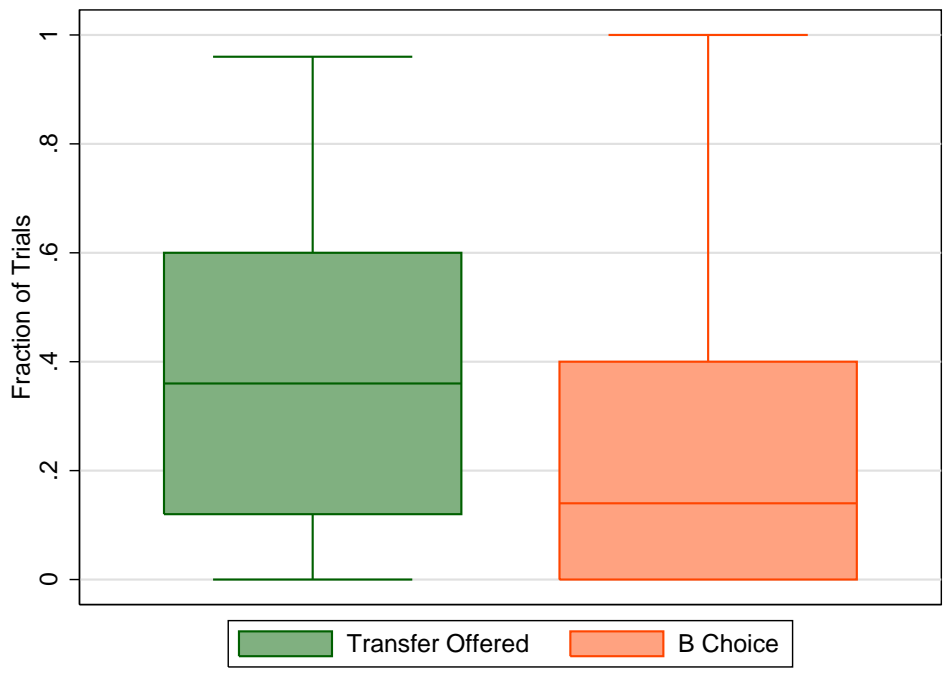

Figure 2: incidence of transfers and B choices

Note. The left bar plots the distribution of the fraction of periods a positive bribe was offered for each pair. The right bar plots the fraction of periods a B choice was made, again for each pair.

Hypothesis 2: Public officials are less likely to choose the corrupt option B in treatment HIGH than in treatment LOW.

\section{Results}

This section presents the results of the experiment. Before moving on to a test of hypotheses 1 and 2, it is important to recall that the Nash equilibrium prediction of the model is that no bribery will take place. However, figure 2 shows that in almost all (34/38) pairs transfer proposals occurred at least once. Moreover, for many pairs transfer proposals were present in a substantial number of rounds; the median number of rounds a bribe was offered is equal to 9 (out of 25). Though somewhat less frequent, B choices also occurred in a large majority of pairs (28/38); the median number of rounds a B decision was made is equal to 3.5 .

In the remainder of this section I will report the results for both the whole sample and for periods 11 to 25; I include the latter to minimize the noise generated by participants who are still trying to learn the game. Note, however, that investigating public officials' corruptibility is only possible for public officials that have been offered at least one bribe. In four pairs (three in treatment LOW, one in treatment HIGH) no bribe was ever offered and these pairs can 
thus not be incorporated into the analysis. ${ }^{16}$

\subsection{Bribe Acceptance}

Hypothesis 1 suggests that public officials in treatment HIGH should be less likely to accept bribes. Figure 3 shows that this is indeed the case. Public officials in treatment LOW accept on average $80 \%$ of proposed bribes $(91 \%$ for periods 11-25), whereas public officials in treatment HIGH accept $44 \%$ of bribes (38\% in periods 11-25). This difference is statistically significant for the whole sample (Mann-Whitney; $N_{L O W}=17, N_{H I G H}=17, \mathrm{z}=3.109, \mathrm{p}=.002$ ) and for periods 11 to 25 (Mann-Whitney; $N_{L O W}=12, N_{H I G H}=15, \mathrm{z}=3.653$, $\mathrm{p}=.000) .{ }^{17}$ Thus, the evidence is in line with hypothesis 1 : increasing public officials' wages reduces the acceptance rate of bribe offers. ${ }^{18}$

This result by itself does not tell us why public officials chose to accept fewer bribes in treatment HIGH. One possible reason that public officials accepted fewer transfers is that public officials in treatment HIGH were offered smaller transfers. This would require that (a) that citizens in treatment HIGH indeed offered smaller transfer and (b) that public officials were more likely to reject smaller transfer offers. However, the data provide little evidence for either claim. Indeed, although proposed transfer size is slightly lower in treatment HIGH (9.57) than in treatment LOW (11.39), the difference between treatments is significant at the $10 \%$ level only for the whole sample (MannWhitney; $\left.N_{L O W}=17, N_{H I G H}=17, \mathrm{z}=1.671, \mathrm{p}=.095\right)$ and not significant for periods 11 to 25 (Mann-Whitney; $N_{L O W}=12, N_{H I G H}=15, \mathrm{z}=1.199$, $\mathrm{p}=.230$ ). Importantly (and perhaps suprisingly) public officials are not more likely to reject smaller transfer offers. ${ }^{19}$ These two findings combined suggest

\footnotetext{
${ }^{16}$ Because of random assignment, whether public officials were ever offered a bribe is random for the whole sample; therefore it is not a problem for any statistics that apply to all periods. For periods 11-25, however, one may worry that attrition may be non-random since bribers may be induced to stop bribing by their matched public official's behavior in the preceding periods. In particular, it may be that the results reported in this section overstate the actual wage effect if bribe rejecting public officials are more likely to drop out in treatment LOW and/or bribe accepting officials are more likely to drop out in treatment HIGH. However, neither scenario seems particularly plausible intuitively and neither is supported by the data. For example, since rejected bribes are costless there is no reason for bribers to stop bribing if bribes are rejected and there is no evidence that bribers who stopped bribing actually faced public officials who were less likely to accept bribes in early periods.

${ }^{17}$ Probit regressions with clustered standard errors by pair yield similar results; $\mathrm{z}=-3.28$, $\mathrm{p}=.001$ for all periods and $\mathrm{z}=-3.89, \mathrm{p}=.000$ for periods $11-25)$. In what follows I will only report the results of regressions if they lead to a different conclusion than the Mann-Whitney test.

${ }^{18}$ In total, 120 bribes were accepted over all sessions; no pair was actually disqualified in the experiment. The probability of no disqualifications with 120 bribes is equal to $(1-.003)^{120}=$ .697.

${ }^{19}$ In a probit regression of the transfer acceptance decision on transfer amount and a con-
} 

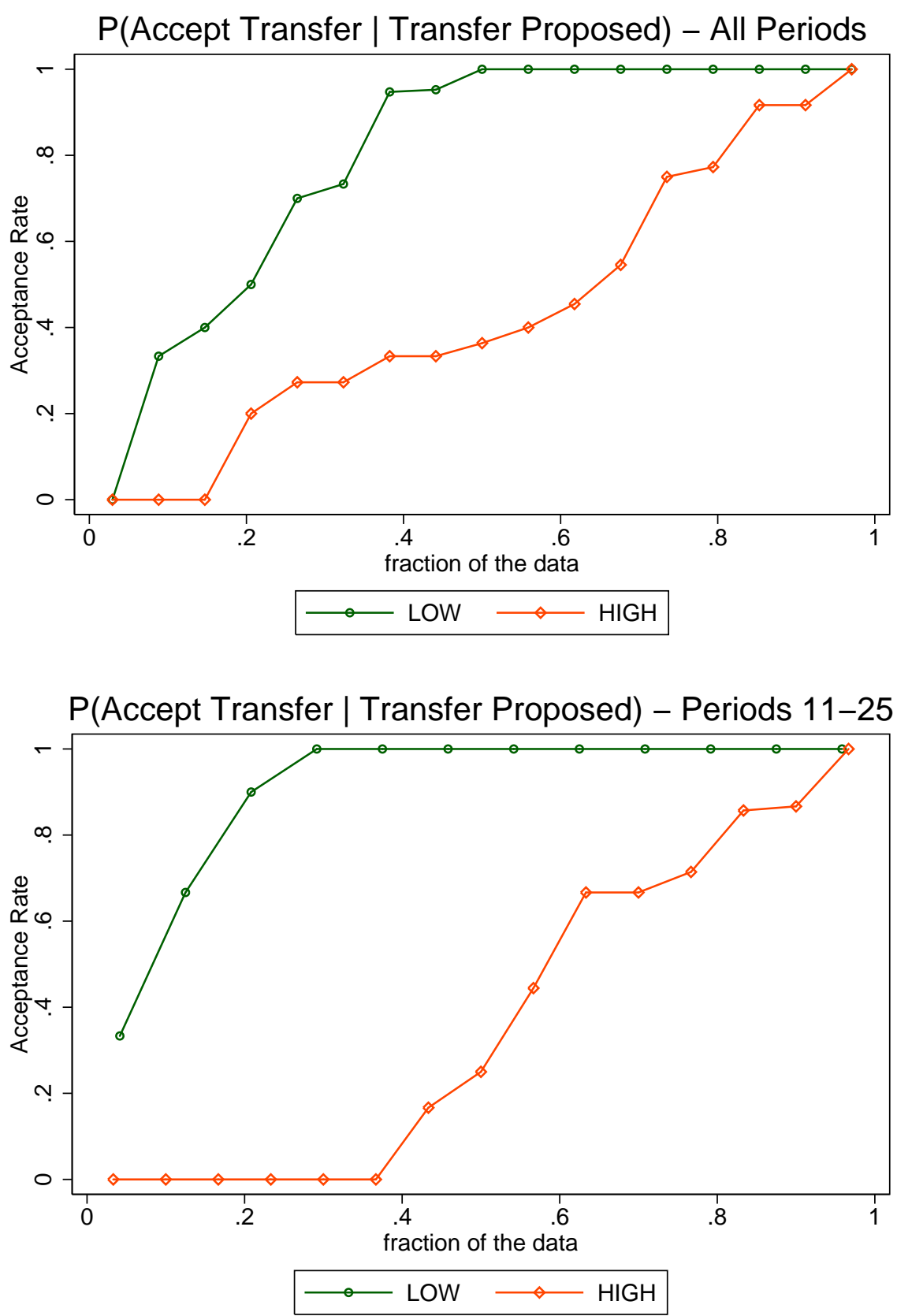

Figure 3: fraction of accepted transfers

Note. The figure plots the cumulative distribution of transfer acceptance rates by pair for both treatments. The upper panel reports the results for all periods, the lower panel reports the results for periods 11-25. 
Table 1: motivations for transfer acceptance

\begin{tabular}{|c|c|c|c|c|}
\hline & $\overline{\text { LOW }}$ & $\overline{\mathrm{HIGH}}$ & Difference & $\overline{P \text { P-value }}$ \\
\hline Own payoff & 4.30 & 3.89 & -.41 & .562 \\
\hline Charity payoff & 3.15 & 4.95 & 1.80 & $.004^{* * *}$ \\
\hline Player 1's payoff & 3.95 & 3.95 & .00 & .952 \\
\hline Observations & 20 & 18 & & \\
\hline
\end{tabular}

Notes. This table gives the average response to three questions in the post-experimental questionnaire. These questions were "In deciding to accept player 1's transfer offer the charity's/my own/player 1's pay-off was an important factor." Answers were reported on a Likert Scale ranging from 1 to 7 . The reported p-values are calculated using Mann-Whitney tests.

that the difference in acceptance rates between treatments cannot be explained by differences in transfer amounts.

Possible supplementary evidence for the motivations of public officials comes from the post-experimental questionnaire. In the questionnaire, public officials answered the following questions: "In deciding to accept player 1's [i.e. the citizen's] transfer offer the charity's/my own/player 1's pay-off was an important factor." Table 1 reports the results of the three questions by treatment. Strikingly, for public officials in treatment HIGH, avoiding damage to the charity was named as the most important factor in deciding (not) to accept bribes, whereas for public officials in treatment LOW, the charity was the least important factor. This finding is not consistent with a monetary cost explanation, since for a monetary cost explanation the payoff of the charity is irrelevant. It does however fit with the idea that nonmonetary costs are increasing in public officials' wages, since high wage public officials care relatively less about their own payoff and the payoff of the briber.

\section{2. $G$ and $B$ Choices}

Thus we have seen that public officials are less likely to accept transfers in treatment HIGH and that this difference is not driven by differences in proposed transfer size but may be driven by differences in non-monetary costs of corruption. This difference in transfer acceptance rates is also reflected by the percentage of $\mathrm{B}$ choices in each treatment. Figure 4 gives an overview of the percentage of B choices conditional on a transfer having been proposed. For the whole experiment, the percentage of $\mathrm{B}$ choices is 15 percentage points lower in treatment HIGH; this difference is not significant (Mann-Whitney; $N_{L O W}=17$,

stant, the p-value for transfer amount equals .268 for the whole sample and .464 for periods $11-25$. 

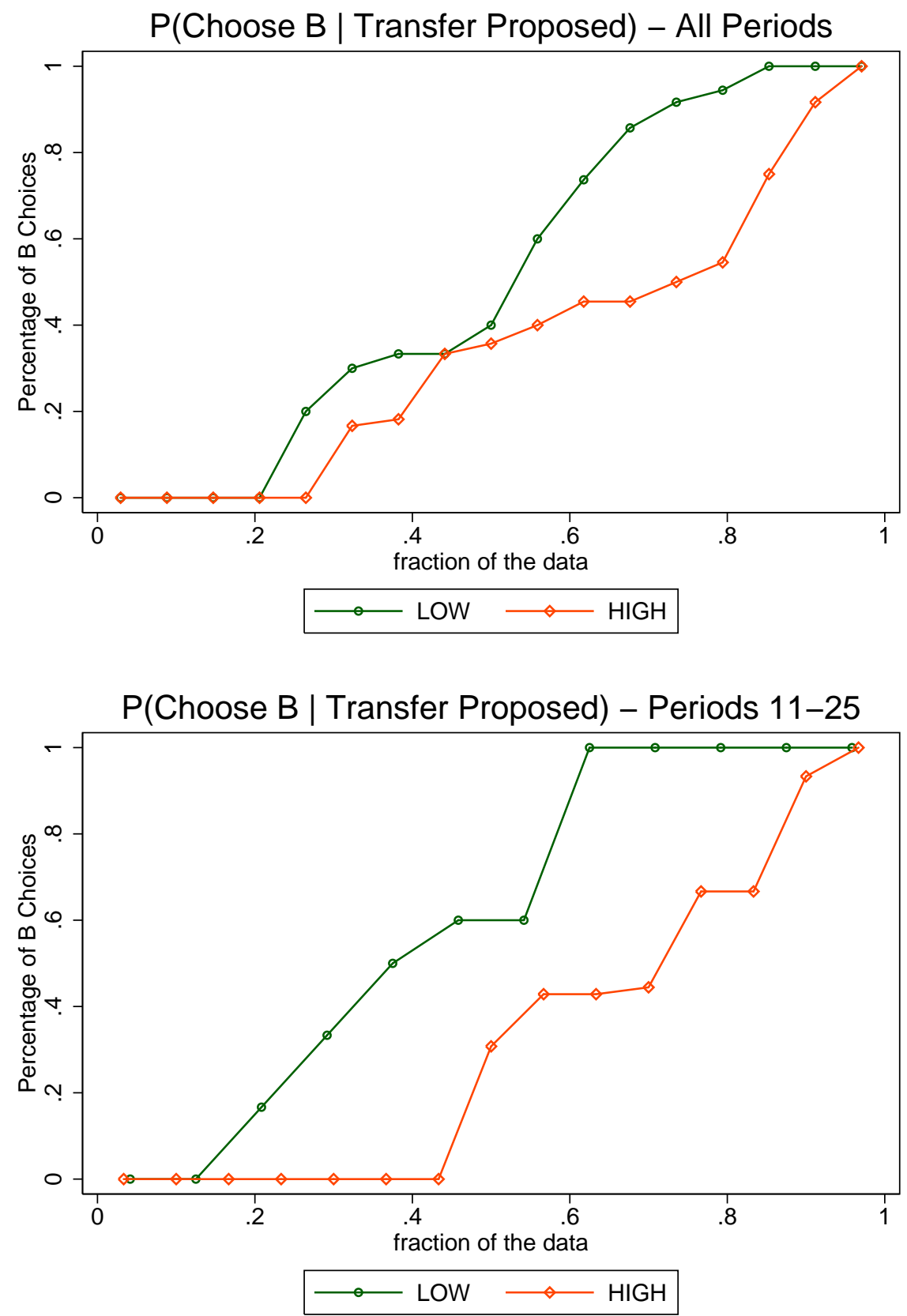

Figure 4: fraction of B choices

Note. The figure plots the cumulative distribution of the percentage of B choices by pair for both treatments. The upper panel reports the results for all periods, the lower panel reports the results for periods 11-25. 
$\left.N_{H I G H}=17, \mathrm{z}=.975, \mathrm{p}=.330\right)$. For periods 11 to 25 the difference becomes larger (27 percentage points) and significant at the $10 \%$ level (Mann-Whitney; $\left.N_{L O W}=12, N_{H I G H}=15, \mathrm{z}=1.876, \mathrm{p}=.061\right) .{ }^{20}$ The difference seems to become more pronounced in later periods; indeed if for instance periods 16-25 are taken instead of periods 11-25 the difference is significant at the $1 \%$ level. Thus, to a some extent the number of $\mathrm{B}$ choices seems to reflect the difference in bribe acceptance rates described above, although the effect is smaller (27 versus 53 percentage points for periods $11-25) .{ }^{21}$

\section{Robustness: Bribery without Monitoring}

Thus far we have seen that increasing public officials' wages greatly decreases the fraction of transfers they accept and slightly decreases the number of corrupt (B) choices they make. This tells us that within the current experimental setting (positive monitoring rate, large penalty to the charity), increasing public officials' wages reduces their corruptibility. This section describes the results of additional sessions that explore the robustness of these findings to setting the monitoring rate to zero. A zero monitoring rate is also of practical interest, since monitoring activities in practice are costly and often subject to corruption themselves; they should as such only be maintained if necessary to reduce corruption levels.

Setting the monitoring rate to zero removes the possibility of disqualification from the experiment and thus removes monetary costs considerations from public officials. Thus, to the extent that monetary costs were relevant with a monitoring rate of .003 , we should expect a smaller treatment effect with a monitoring rate of zero. However, monetary costs were already quite small even with monitoring. Indeed, with monitoring the only predicted difference for risk neutral public officials is that they should accept all bribes larger than 3 in treatment LOW and all bribes larger than 5 in treatment HIGH. ${ }^{22}$ In the

\footnotetext{
${ }^{20}$ Incidentally, there are no gender differences for either the transfer acceptance decision or the number of B choices. This is true for the two treatments taken separately as well as jointly. The only gender difference appears with citizens; female citizens are more likely to attempt to bribe a public official than male citizens $(\mathrm{p}=0.025)$.

${ }^{21}$ The reason the difference between $\mathrm{B}$ choices is smaller than the difference between transfer rates is due to two factors. For one, not all accepted transfers lead to B choices; the number of accepted transfers leading to $\mathrm{G}$ choices is equal to $32.4 \%$ for treatment LOW and $26.3 \%$ for treatment HIGH. For another, the fraction of B choices taken after rejected transfers is not equal to zero (it is equal to $6.7 \%$ and $13.3 \%$ for treatments LOW and HIGH respectively).

${ }^{22}$ In the experiment, average earnings over all periods for public officials in treatment LOW and HIGH were 943 and 1420 points respectively. Thus, accepting a single bribe leads to an expected loss from disqualification equal to $.003 * 943=2.83$ and $.003 * 1420=4.26$ for treatments LOW and HIGH respectively. Risk-neutral public officials should only accept
} 
Table 2: overview of transfer acceptance rates

\begin{tabular}{ccccc}
\hline \hline & LOW & HIGH & Difference & P-value \\
\hline Monitoring & .91 & .38 & -.53 & $.000^{* * *}$ \\
No Monitoring & .97 & .79 & -.18 & $.016^{* *}$ \\
Difference & .06 & .41 & .35 & $.013^{* *}$ \\
P-value & .368 & $.002^{* * *}$ & $.013^{* *}$ & \\
\hline \hline
\end{tabular}

$*$ significant at $10 \% ; * *$ significant at $5 \% ; * * *$ significant at $1 \%$

Notes. This table gives the mean transfer acceptance rates conditional on a transfer being offered. That is, first I computed the average acceptance probability for every pair and then averaged these probabilities over all pair for every treatment. The reported p-values for the difference estimators are calculated using Mann-Whitney tests. The p-value for the differencein-difference estimator (.35) is calculated using an OLS estimator of the transfer acceptance decision on a treatment dummy, a dummy for monitoring and an interaction of the two dummies; the p-value corresponds to the p-value of the interaction term. In both cases only periods 11 to 25 are used, in the latter case standard errors are clustered at the pair level.

experiment, however, only $5 \%$ of proposed bribes were equal to 3 or 4 . Moreover, we saw that bribe size does not affect the probability that a transfer is accepted. Thus with risk neutrality monetary costs can only explain a small fraction of the total difference between treatments. ${ }^{23}$

Setting the monitoring rate to zero may also affect the nonmonetary costs of corruption. In particular, a positive monitoring rate may be a signal to public officials that accepting a transfer is not a moral or normative thing to do. Without monitoring this signal disappears, which could induce public officials to be more corrupt.

To investigate the influence of setting the monitoring rate to zero I ran an additional four sessions in June 2011. These sessions were identical to the sessions described in the previous sections, except that the monitoring rate was equal to zero instead of .003. In total, 84 subjects took part in these sessions, earning between 13.42 and 21.88 euros. Charities earned between 11.00 and 34.10 euros, with an average of 25.50 euros.

To analyze the influence of monitoring on the influence of wage increases on corruptibility, I compare the results of these sessions with the results of the previous section. Figure 5 and table 2 give the transfer acceptance rates for both treatment HIGH and treatment LOW for sessions with monitoring and sessions without monitoring. In sessions without monitoring, the difference in

bribes that exceed the expected loss from disqualification.

${ }^{23}$ Introducing risk aversion would predict stronger differences, although with small probabilities risk seeking is more commonly observed than risk aversion. See e.g. Tversky and Kahneman, 1992 and Abbink et al., 2002 for evidence that subjects underestimate disqualification probabilities in a bribery game. 

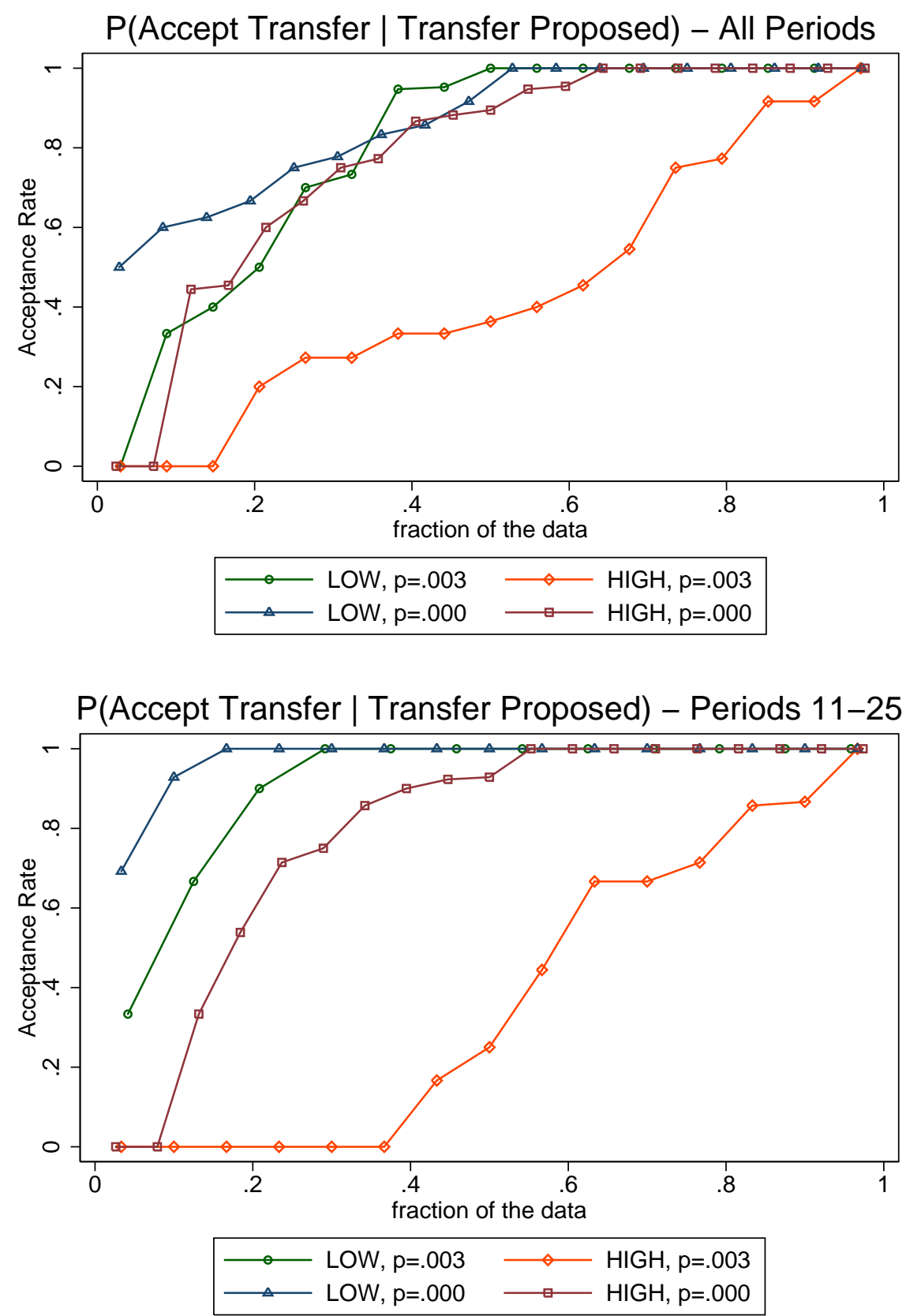

Figure 5: transfer acceptance rate with and without monitoring

Note. The figure plots the cumulative distribution of transfer acceptance rates by pair for both sessions with monitoring and sessions without monitoring. The top panel displays the results for all periods and the lower panel displays the results for periods $11-25$. 
Table 3: importance of charity in transfer acceptance

\begin{tabular}{ccccc}
\hline \hline & LOW & HIGH & Difference & P-value \\
\hline Monitoring & 3.15 & 4.95 & 1.80 & $.004^{* * *}$ \\
No Monitoring & 3.78 & 3.48 & -.30 & .565 \\
Difference & .63 & -1.47 & 2.10 & $.015^{* *}$ \\
P-value & .236 & $.035^{* *}$ & $.015^{* *}$ & \\
\hline \hline
\end{tabular}

* significant at $10 \% ; * *$ significant at $5 \% ; * * *$ significant at $1 \%$

Notes. This table gives the average response to the question "In deciding to accept player 1's transfer offer the charity's pay-off was an important factor" in the post-experimental questionnaire. Answers were reported on a Likert Scale ranging from 1 to 7 . The reported pvalues for the difference estimators are calculated using Mann-Whitney tests. The p-value for the difference-in-difference estimator (2.10) is calculated using an OLS estimator of the transfer acceptance decision on a treatment dummy, a dummy for monitoring and an interaction of the two dummies; the p-value corresponds to the p-value of the interaction term.

transfer acceptance rates falls from .53 to .18 in periods 11 to $25(\mathrm{p}=0.013)$ and from .36 to .09 in all periods $(\mathrm{p}=0.020)$. Table 2 shows that this change is driven almost exclusively by the greater corruptibility of HIGH wage public officials in sessions without monitoring. As a consequence, the difference in the percentage of $\mathrm{B}$ choices falls from 27 percentage points to 4 percentage points in periods 11-25 and from 15 percentage points to 1 percentage point in all periods. Finally, table 3 shows that self-reported care for the charity in treatment HIGH drops to the level of treatment LOW in riskless sessions, whereas it was substantially higher in sessions with monitoring.

All in all this suggests that the evidence presented in the previous section is only partially robust to the removal of monitoring. In fact, it suggests that both monitoring and a high wage are necessary to decrease corruption. However, this result may also be due to a ceiling effect in the transfer acceptance rates in treatment LOW. Even with monitoring public officials in treatment LOW accepted $91 \%$ of proposed transfers on average in periods 11-25, meaning there was hardly any scope for the transfer acceptance rate to increase. On the other hand, with monitoring the average acceptance rate was only $38 \%$ in treatment $\mathrm{HIGH}$, leaving a lot of room for the transfer acceptance rate to increase.

\section{Discussion}

In this study, I have investigated the link between public officials' wages and their corruptibility. The results show that increasing the wage of public officials dramatically reduces their corruptibility. In particular, experienced low wage public officials accept $91 \%$ of bribes, whereas experienced high wage public officials accept only $38 \%$. Moreover, high wage public officials are 27 
percentage points less likely to choose the corrupt option. A robustness check suggests that a positive monitoring rate may be necessary for higher salaries to affect the corruptibility of public officials.

All in all, these results provide greater support for a link between wages and bribery than previous experimental studies. The contrast with Abbink (2002) is particularly illuminating since its experiment is based on the same bribery model and also has a positive level of monitoring. The difference in findings suggests that the reference wage is important; if a third party is used as a reference wage as in Abbink, the relative wage of the public official does not seem to matter. By contrast, if the briber is used as the reference wage as in this study, there is a large and statistically significant effect. This suggests that in empirical studies that investigate the link between wages and corruption, it is important to use an appropriate reference wage. In particular, if the reference wage that is used in the study is not used as a reference wage by most public officials, one will not find a relationship between wages and corruption even such a relationship does exist with the appropriate reference wage. Taken together with the results of Abbink, this study could thus provide an explanation for the mixed results reported in both laboratory and field studies.

As the robustness check showed, a positive monitoring rate seems to be necessary for high wages to decrease corruption. At the same time, even the positive monitoring rate used in the experiment was very small. This suggests that the exact size of the monitoring rate may not be important for small monitoring rates; rather the presence monitoring may serve as a signal to public officials that accepting bribes is not a moral thing to do. Even if nonmonetary costs are important, a small but positive level of monitoring may thus be necessary to reduce corruption.

For future experimental work, several extensions are possible. It may for example be interesting to vary the wage of public officials within the same session. To the extent that the wages of colleagues can also serve as reference wages, it may be expected that public officials with wages that are higher than both colleagues and bribers will be even less likely to accept bribes. Another possibility would be to allow public officials to solicit bribes rather than have them wait for bribers to offer one, as in Barr and Serra (2010). These extensions may help provide additional insights on the conditions that need to be met for the link between wages and corruptibility to appear. 


\section{Acknowledgments}

I would like to thank Adrian de Groot Ruiz, Ernst Fehr, Guillaume Frechette, Jona Linde, Theo Offerman, Elke Renner, David Rojo Arjona, Andy Schotter, Joep Sonnemans and seminar participants at the University of Amsterdam, the Tinbergen Institute, the University of Maastricht, the 2011 ESA World Meeting, the 2011 CREED-CEDEX-UEA meeting in Nottingham and the 2011 CREED-CESS meeting in New York for helpful comments and suggestions. I am especially grateful to Francisca Then for pointing me towards the study of experiments on corruption and helping me in running the experiment. Financial support from the University of Amsterdam Research Priority Area in Behavioral Economics is gratefully acknowledged.

\section{References}

Abbink, K., 2002. Fair salaries and the moral costs of corruption. Centre for Decision research and Experimental economics (CeDEx) Working Paper (May), $2-7$.

URL http://128.243.80.167/cedex/documents/papers/2002-05.pdf

Abbink, K., Nov. 2004. Staff rotation as an anti-corruption policy: an experimental study. European Journal of Political Economy 20 (4), 887-906.

URL http://linkinghub.elsevier.com/retrieve/pii/S0176268003000843

Abbink, K., 2006. Laboratory experiments on corruption. In: Rose-Ackerman, S. (Ed.), International handbook on the economics of corruption. Edward Elgar Publishing Inc., Northampton, pp. 418-437.

Abbink, K., Hennig-Schmidt, H., Jun. 2006. Neutral versus loaded instructions in a bribery experiment. Experimental Economics 9 (2), 103-121.

URL http://www . springerlink. com/index/10.1007/s10683-006-5385-z

Abbink, K., Irlenbusch, B., Renner, E., Oct. 2002. An Experimental Bribery Game. Journal of Law, Economics, and Organization 18 (2), 428-454.

URL http://jleo.oupjournals.org/cgi/doi/10.1093/jleo/18.2.428

Akerlof, G., Yellen, J., 1990. The fair wage-effort hypothesis and unemployment. The Quarterly Journal of Economics 105 (2), 255.

URL http://qje.oxfordjournals.org/content/105/2/255.short

Armantier, O., Boly, A., 2008. Can corruption be studied in the lab? Comparing a field and a lab experiment. CIRANO Working Papers.

URL http://papers.ssrn.com/sol3/papers. cfm?abstract_id=1324120

Azfar, O., Nelson, W. R., Jan. 2007. Transparency, wages, and the separation of powers: An experimental analysis of corruption. Public Choice 130 (3-4), 
471-493.

URL http://www .springerlink.com/index/10.1007/s11127-006-9101-5

Barr, A., Lindelow, M., Serneels, P., Oct. 2009. Corruption in public service delivery: An experimental analysis. Journal of Economic Behavior \& Organization 72 (1), 225-239.

URL http://linkinghub.elsevier.com/retrieve/pii/S0167268109001838

Barr, A., Serra, D., Dec. 2010. Corruption and culture: An experimental analysis. Journal of Public Economics 94 (11-12), 862-869.

URL http://linkinghub.elsevier.com/retrieve/pii/S0047272710000927

Becker, G. S., Stigler, G. J., Jan. 1974. Law Enforcement, Malfeasance, and Compensation of Enforcers. The Journal of Legal Studies 3 (1), 1.

URL http://www. journals .uchicago.edu/doi/abs/10.1086/467507

Buss, A. H., Perry, M., Sep. 1992. The aggression questionnaire. Journal of personality and social psychology $63(3), 452-9$.

URL http://www.ncbi.nlm.nih.gov/pubmed/1403624

Buunk, B. P., Mussweiler, T., Sep. 2001. New directions in social comparison research. European Journal of Social Psychology 31 (5), 467-475.

URL http://doi.wiley.com/10.1002/ejsp.77

Cameron, L., Chaudhuri, A., Erkal, N., Gangadharan, L., Aug. 2009. Propensities to engage in and punish corrupt behavior: Experimental evidence from Australia, India, Indonesia and Singapore. Journal of Public Economics 93 (7-8), 843-851.

URL http://linkinghub.elsevier.com/retrieve/pii/S0047272709000334

Di Tella, R., Schargrodsky, E., Apr. 2003. The Role of Wages and Auditing during a Crackdown on Corruption in the City of Buenos Aires. The Journal of Law and Economics 46 (1), 269-292.

URL http://www.journals.uchicago.edu/doi/abs/10.1086/345578

Drugov, M., Hamman, J., Serra, D., 2011. Intermediaries in Corruption: An Experiment. Working Paper Series.

URL http://papers.ssrn.com/sol3/papers. cfm?abstract_id=1838591

Fehr, E., Schmidt, K. M., Aug. 1999. A Theory of Fairness, Competition, and Cooperation. The Quarterly Journal of Economics 114 (3), 817-868.

URL http://qje.oxfordjournals .org/cgi/doi/10.1162/003355399556151

Festinger, L., 1954. A theory of social comparison processes. Human relations 7 (2), 117-140.

Fisman, R., Miguel, E., Dec. 2007. Corruption, Norms, and Legal Enforcement: Evidence from Diplomatic Parking Tickets. Journal of Political Economy 115 (6), 1020-1048.

URL http://www.jstor.org/stable/10.1086/527495 
Frank, B., Schulze, G., Sep. 2000. Does economics make citizens corrupt? Journal of Economic Behavior \& Organization 43 (1), 101-113.

URL http://linkinghub.elsevier.com/retrieve/pii/S0167268100001116

Jacquemet, N., 2005. Corruption as Betrayal : Experimental Evidence on Corruption Under Delegation. Centre National de la Recherce Scientifique Working Paper.

Linde, J., Sonnemans, J., Nov. 2012. Social comparison and risky choices. Journal of Risk and Uncertainty 44 (1), 45-72.

URL http://www.springerlink. com/index/R6X36X128621T040.pdf

Olken, B., Apr. 2007. Monitoring Corruption: Evidence from a Field Experiment in Indonesia. Journal of Political Economy 115 (2), 200-249.

URL http://www.jstor.org/stable/10.1086/517935

Rabl, T., Kühlmann, T. M., Sep. 2008. Understanding Corruption in Organizations Development and Empirical Assessment of an Action Model. Journal of Business Ethics 82 (2), 477-495.

URL http://www . springerlink.com/index/10.1007/s10551-008-9898-6

Rauch, J., Evans, P., Jan. 2000. Bureaucratic structure and bureaucratic performance in less developed countries. Journal of Public Economics 75 (1), 49-71. URL http://linkinghub.elsevier.com/retrieve/pii/S0047272799000444

Rose-Ackerman, S., Feb. 1975. The economics of corruption. Journal of Public Economics 4 (2), 187-203.

URL http://linkinghub.elsevier.com/retrieve/pii/0047272775900171

Suls, J., Martin, R., Wheeler, L., Oct. 2002. Social Comparison: Why, With Whom, and With What Effect? Current Directions in Psychological Science $11(5), 159-163$.

URL http://cdp.sagepub.com/lookup/doi/10.1111/1467-8721.00191

Svensson, J., Feb. 2003. Who Must Pay Bribes and How Much? Evidence from a Cross Section of Firms. The Quarterly Journal of Economics 118 (1), 207-230.

URL http://qje.oxfordjournals.org/cgi/doi/10.1162/00335530360535180

Svensson, J., Sep. 2005. Eight Questions about Corruption. Journal of Economic Perspectives 19 (3), 19-42.

URL http://pubs . aeaweb.org/doi/abs/10.1257/089533005774357860

Sweeney, P. D., McFarlin, D. B., Jun. 2004. Social comparisons and income satisfaction: A cross-national examination. Journal of Occupational and Organizational Psychology 77 (2), 149-154.

URL http://doi.wiley.com/10.1348/096317904774202117

Treisman, D., Jun. 2000. The causes of corruption: a cross-national study. Journal of Public Economics 76 (3), 399-457.

URL http://linkinghub.elsevier.com/retrieve/pii/S0047272799000924 
Tversky, A., Kahneman, D., Oct. 1992. Advances in prospect theory: Cumulative representation of uncertainty. Journal of Risk and Uncertainty 5 (4), 297-323.

URL http://www. springerlink.com/index/10.1007/BF00122574

Van Rijckeghem, C., Weder, B., Aug. 2001. Bureaucratic corruption and the rate of temptation: do wages in the civil service affect corruption, and by how much? Journal of Development Economics 65 (2), 307-331.

URL http://linkinghub.elsevier.com/retrieve/pii/S0304387801001390

\section{AppendixA. Instructions}

Welcome to the CREED laboratory. Please read the following instructions carefully. $^{24}$

In today's experiment, there are two types of participants: Player 1 and Player 2. Your type will be randomly drawn after everyone has finished the instructions. You will then also be randomly matched to a player of the other type. Both your type and the player you are matched with will remain unchanged throughout the experiment.

All in all the experiment consists of 25 periods. The payment you receive at the end of the experiment depends on the decisions you make. Moreover, you will be able to earn money for a charity. The currency of the experiment is the experimental franc. At the end of the experiment, all francs you earned will be converted into euros at a rate of 100 francs per euro, such that 1000 francs are worth 10 euros. You will also receive a show-up fee of 7 euros.

\section{Decision Situation}

Every period in this experiment consists of 5 stages, which will always take place in the following order:

\section{Stage 1: Transfer or no Transfer}

Player one decides whether or not he wants to transfer an amount to player two. If he does, then the period is continued with stage 2 . If player one decides not to transfer an amount, then the period continues with stage five.

\section{Stage 2: The Amount to Be Transferred}

Player one decides on the amount to be transferred to player two. The transferred amount can be any whole number greater than zero. The period then continues with stage 3 .

\footnotetext{
${ }^{24}$ These instructions are the instructions for both public officials and citizens in the LOW wage treatment with monitoring. In sessions without monitoring, stage IV is omitted and stage $\mathrm{V}$ is called stage IV instead.
} 


\section{Stage 3: Acceptance or Rejection of the Transfer}

Player two then decides whether he accepts or rejects the proposed transfer. If player two decides to accept the transfer, the proposed amount is removed from player 1's credit and added to player 2's credit. The period then continues with stage 4 . If player two rejects the transfer, then the credits remain unchanged. The period is then continued with stage four.

\section{Stage 4: Possibility of Getting Disqualified}

If player 2 decided to accept the transfer in stage 3 , a number out of the range from 0 to 999 is randomly drawn. If the number is 0,1 or 2 , then both player 1 and player 2 are disqualified. That means that the experiment ends for these two players and all their previous earnings are canceled. (At the end of the experiment, both players receive only their show-up fee.) The two disqualified participants fill in a questionnaire until the experiment has ended. For the other participants, the experiment continues normally. If the randomly drawn number is $3,4, \ldots, 998$, or 999 , the period is continued with stage 5 (see next page).

Stage 5: Player 2 Chooses Between $X$ and $Y$

\begin{tabular}{|crr|}
\hline & $\mathrm{X}$ & $\mathrm{Y}$ \\
Player 1 & 36 & 56 \\
Player 2 & 36 & 30 \\
Charity & 0 & -30 \\
\hline
\end{tabular}

Player 2 chooses one of the alternatives $\mathrm{X}$ or $\mathrm{Y}$. If player 2 selects alternative $\underline{\mathrm{X}}$, then his credit is increased by 36 and the credit of player 1 is increased by 36 (as in the table above). The credit of the charity remains unchanged. If player 2 selects alternative $\underline{Y}$, then his credit is increased by 30 and the credit of player 1 is increased by 56 . The credits of the charity are decreased by 30 francs.

There will be only one charity for this experiment. The charity starts off with a total of 5000 francs, which is equal to 50 euros. The final donation depends on the decisions made by the participants in the experiment. The donation will be strictly anonymous; no mention will be made of either the UvA, CREED or any participant of this experiment.

After stage 5, the period has ended. Overall pay-offs are the sum of all changes of credits during the 5 stages of the period.

\section{The Pay-Offs}

The decision situation will be repeated for 25 periods. You receive your earnings at the end of the experiment, where the exchange rate is 1 euro for 100 francs. In addition you will receive a show-up fee of 7 euros.

\section{Question 1}

Suppose you are player 2 and player 1 has proposed a transfer of 8 . If you accept, what will be your (player 2's) pay-off if you choose option X? What will 
be player 1's pay-off in this case? What will be the pay-offs for option Y? TIP: look up the values for $\mathrm{X}$ and $\mathrm{Y}$ on one of the previous pages or on the printout of the instructions.

\section{Question 2}

In this experiment, there are a total of 20 participants, such that there are 10 pairs. Suppose that in a certain period there are 5 pairs in which player 2 chooses option Y. How many francs will the charity lose in this period?

\section{Charities}

For this experiment, we have selected a total of five charities. At the end of the experiment, we will pick the charity selected by one randomly determined person. Thus, the likelihood that a charity is picked is proportional to the number of people that picked this charity. For example, a charity chosen by six people will be three times more likely to be picked than a charity chosen by two people. If you would like to support another charity, you can select option 'F: Other Charity' and type the name of the charity in the text box. We must emphasize that a self-chosen charity will only be paid out if it passes a 'fitand-proper-charity' test. For example, organizations like AlQaeda or your best friend's holiday fund will be considered invalid charities. If an invalid option is drawn, we will redraw until a valid charity has been selected.

A. UNICEF: Created by the United Nations General Assembly on December 11, 1946, to provide emergency food and health care to children in countries that had been devastated by World War II. Presently, its activities include promoting childrens rights, and securing worldwide visibility for children threatened by poverty, disasters, armed conflict, abuse and exploitation. UNICEF was awarded the Nobel Peace Prize in 1965.

B. WWF/WNF: Founded on September 11, 1961, its official mission is "to halt the destruction of our environment". Currently, the WWF focuses on restoring populations of 36 species (including elephants and tunas) as well as conserving 25 globally important ecoregions (including the Amazon Forest).

C. Red Cross: Founded on February 9, 1863, its official mission is "to stand for the protection of the life and dignity of victims of international and internal armed conflicts." Amongst its activities, it attempts to organize nursing and care for those who are wounded on the battlefield; it also supervises the treatment of prisoners of war.

D. Cliniclowns: Founded in 1992, its goal is to cheer up severely sick or handicapped children to help them recuperate from their ailments. Its most important activity is to send clowns to visit children's wards to cheer up the children, but it has also started a theatre tour for children with multiple disabilities.

E. Prins Bernhard Cultuurfonds: Founded in 1940 by Prince Bernhard of the Netherlands, its goal is to support projects that work to preserve Dutch cultural and natural heritage. Its activities include awarding prices and scholarships to talented musicians, poets and other artists. On average, it supports 4000 projects per year. 


\section{AppendixB. Decision Screen}

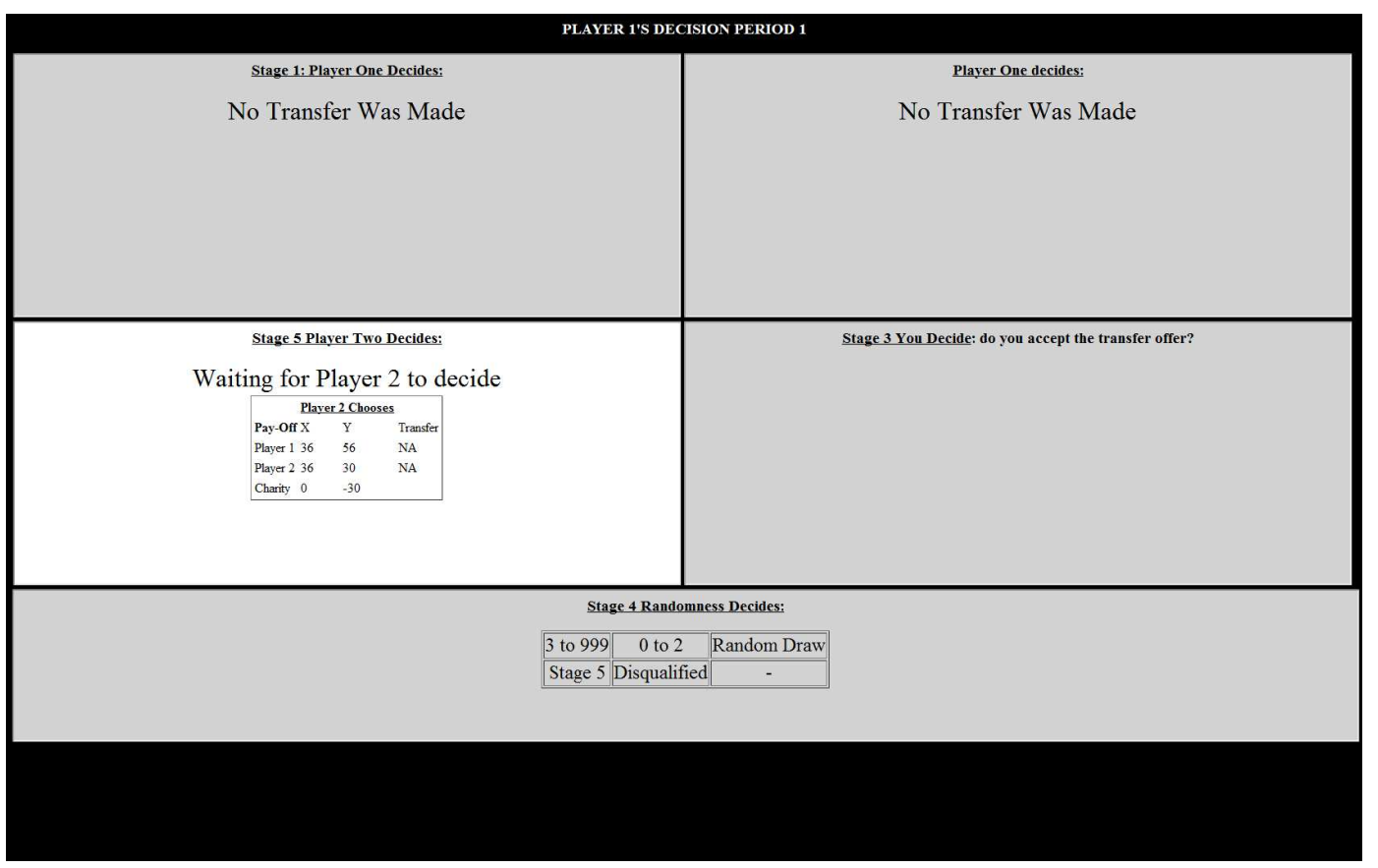

